\title{
A review on functional ingredients in red meat products
}

\author{
Tahreem Kausar, Entesar Hanan, Omeera Ayob, Bushra Praween \& ZRAA Azad*
}

Department of Food Technology, School of Interdisciplinary Sciences and Technology, Jamia Hamdard, Hamdard Nagar, New Delhi-62, India; ZRAA Azad - *Email: zrazad@jamiahamdard.ac.in

Received April 12, 2019; Accepted April 26, 2019; Published May 15, 2019

DOI: $10.6026 / 97320630015358$

Abstract

Meat and meat products are important foods with essential nutritional components such as essential amino acids, fatty acids, vitamins and minerals that form a significant component for the normal physiological and biochemical processes. However, the main drawback of meat and meat products is the absence of dietary fibre and the presence of saturated fat. Value improvement can be done by the incorporation of functional ingredients into the meat products. The use of functional ingredients in meat products offers processors the opportunity to enhance the functional and nutritional value of their products. Vegetable proteins, dietary fibre, cereal by-products, fruits, legumes, spices, herbs, and lactic acid bacteria that have been used alone or in combination for the enhancement of the functional value of meat and meat products were studied. Hence, the current review focuses on the functional ingredients incorporated in meat products.

Keywords: Enrichment, functional ingredients, meat, processing and value addition

\section{Background:}

Foods are important and suitable vehicles for the human being to convey the essential nutrients that may improve their health. Animal meat is of high biological value and a good source of proteins in many countries. Meat and meat products are ideal sources of soluble minerals, vitamins, essential fats, amino acids and many other nutrients having a specific function to the body [1]. There is an increasing demand for healthier meat and meat products containing low levels of fat, cholesterol, reduced content of sodium chloride and nitrite, updated fatty acid profile composition and added health-enhancing ingredients among consumers worldwide. Recently, there is an increasing concern about health-oriented functional meat products as a result of drawbacks incorporated with muscle foods and its related health hazards. Meat is a good source of omega-3 fatty acids, proteins, vitamin B12 and high levels of iron [2]. Meat and meat products can be modified by the addition of certain ingredients that eliminate or reduce harmful components from the body and are thus beneficial to health. Meat products incorporated with dietary fibres are best meat substitutes because of their functional and nutritional values [3]. Goat meat is the most staple red meat taken in human diets. It is universally accepted but influenced by traditions and socioeconomic conditions; as a result, influencing customer preference $[4,5]$. Goat meat and beef were also slightly more liked due to preferences for texture and muscles. Goat meat is dark red with a coarse texture and has a noticeable variety of flavour and aroma from lamb and beef $[6,7]$. According to the consumer, meat and meat product consumption is unhealthy due to the presence of cholesterol, synthetic antioxidants; antimicrobial contents that result in some degenerative diseases and saturated fats [8].

Functional food is mainly a conventional food, which is consumed as a part of a usual diet. The term functional food was firstly used by Japan in the 1980s to dedicate food products that are fortified with specific constituents with beneficial physiological effects [9]. Foods that are marketed under functional category contain 


\section{BIOINFORMATION \\ Discovery at the interface of physical and biological sciences}

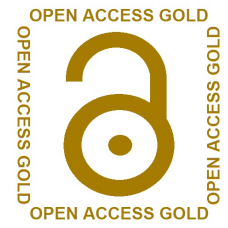

added technologically developed ingredients [10], and important biologically active compounds [11]. These foods provide health benefits by mediating specific physiological functions in the body and are marketed and consumed for this value-added property. Reformulation of meat is achieved by the addition of fibres, proteins, polyunsaturated fatty acids (PUFA), antioxidants, etc. A functional food should possess certain requirements, i.e. it should be derived from a naturally occurring ingredient; consumed as a part of a regular diet and should be involved in the regulation of certain human process such as age delaying, risk prevention from diseases and improvement in immunological abilities [12]. Sometimes in functional foods, one or more additional ingredients are added, that shows health benefits above and beyond as compared to those of regular foods [13]. Functional food is widely used in developed countries due to their high shelf life, advanced food technology, health benefits, and known importance. Food nowadays is not only eaten for hunger satisfaction and necessary nutrition but also for preventing nutrition-related disorders and for mental-physical well being of an individual [14]. Hence, food nutritionist and technologist are targeting to develop functional meat products with great efforts that possess natural antioxidants and antimicrobials, low fat, lesser sodium content, enriched with dietary fibres and $\omega-3$ and $\omega-6$ fatty acids [15] as shown in Figure 1.

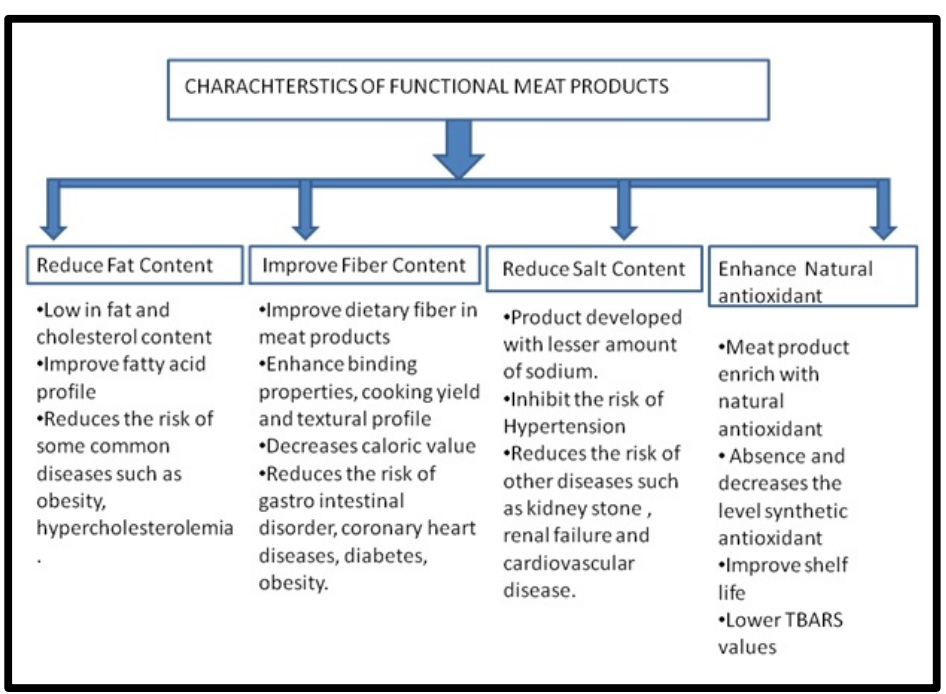

Figure 1: Characteristics of functional meat products

\section{Incorporation of dietary fiber:}

The plant-based derivatives like fruits, nuts, vegetables, herbs, and spices are mainly used now a day for the production of modified and healthier meat products with improved shelf life. Dietary fibers and antioxidants addition are the most approaching step in the development of novel meat products. The fiber incorporation is on demand because of its technological use and benefits to human health [16]. Foods with high dietary fiber proportion are reported to reduce the risk of obesity, colon cancer, cardiovascular diseases and various other disorders [17] as shown in Figure 2. Various dietary fibers have been used in meat products for determination of proper beneficial health effects and also as potential fat substitutes [18].

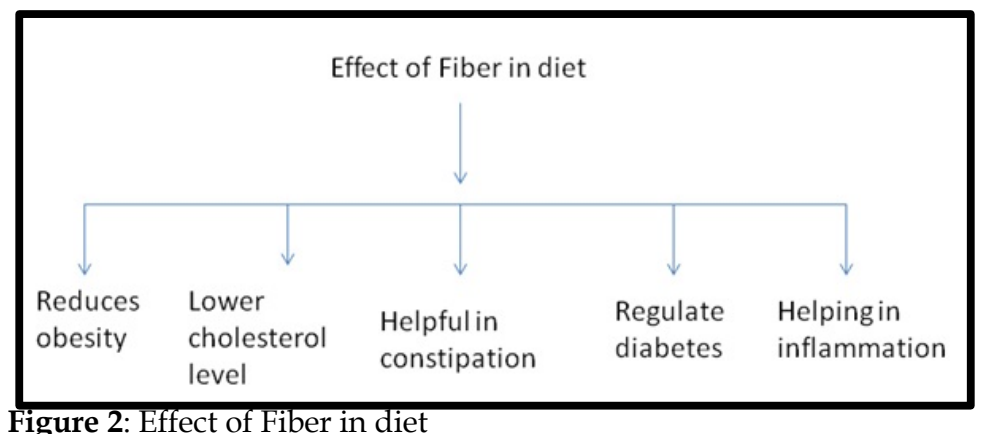

Dietary fibers (DF) are defined as residues of eatable plant fragments and carbohydrates that can't be absorbed or assimilated and are indigestible in the small intestine of human [19]. It promotes important physiological effects such as laxation and blood glucose and cholesterol attenuation [20]. Dietary fibers are composed of various categories of ingredients namely oligosaccharides and polysaccharides, i.e., cellulose, hemicelluloses, pectic materials, inulin, lignin and other components like waxes, phytates, cutin, saponins, and resistant proteins and polyphenols [21]. Various DF sources are wheat, oat, and rice bran; sugar beet; soy; brewer's spent grain; pea; vegetables; cereal grains; woody plants; fruits; legumes; leguminous plants, psyllium, etc. have been incorporated in the recipes of certain meat products namely meatballs, patties, and sausages for nutritious daily regime improvement. DF incorporation in meat products improves functional properties such as water retention, lubrication, rheological properties, emulsion stability, neutral flavor and modification in texture [22]. It also improves cooking yield, reduces formulation costs and enhances the palatability. Dietary Fiber intake through meat substituted with fruits, vegetables, and certain grains protects against cardiovascular diseases, diverticulitis, constipation, irritable colon, colon cancer and diabetes [23]. Dietary fibers also act as a fat replacer. It also decreases plasma and LDLcholesterol levels, reduces the risk of dietary related problems like obesity, coronary diseases, gastrointestinal disorders, i.e., 

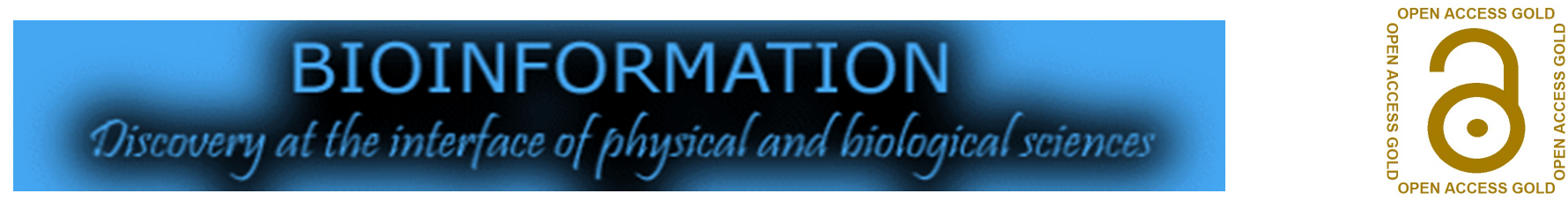

constipation, inflammatory bowel diseases, etc [24]. Various food industries manufacture modified energy-dense foods by adding vegetable and fruit fibers. Fiber addition in meat products is considered as suitable and thus increases the cooking yield and texture in cooked meat products because of its water and fat binding properties [12]. Supplementation of DF increases the bulk and reduces cooking losses in meat products. It offers no or fever changes in textural parameters by improving water-binding abilities and also enhances economic advantages for the consumers and processors [25]. The dietary fiber in meat products is mainly considered clinically better as compared to that of traditional meat products [22]. Also, the incorporation of dietary fiber in meat products leads to the development of novel meat products. Various types of dietary fibers improve the quality of the meat products are given in Table 1.

Table 1: Functional ingredients as fiber content in meat products

\begin{tabular}{|c|c|c|c|c|}
\hline S. No & Functional ingredients & Developed Product & Effect on meat product quality & Reference \\
\hline 1 & Pumpkin & Chicken Sausages & Fiber enrich product & [26] \\
\hline 2 & Psyllium husk & Chicken burger patties & Improve Dietary fiber content and reduces fat cholesterol content & [27] \\
\hline 3 & Flax seed oil and rice bran & Beef burger patties & $\begin{array}{l}\text { Diminish total lipid and saturated fatty acid } \\
\text { Improve dietary fiber }\end{array}$ & [28] \\
\hline 4 & Carrot and Lemon Fiber & Beef hamburger & Low fat and cholesterol content & [29] \\
\hline 5 & Green banana and soybean hulls flours & Chicken nuggets & Improve dietary fiber and boost instrumental texture and color properties & [30] \\
\hline 6 & Guava & Sheep Meat Nuggets & Improve antioxidant and dietary fiber & {$[31]$} \\
\hline 7 & Psyllium husk and fenugreek leaves & Goat meat patties & Improve fiber content and antioxidant properties & [32] \\
\hline 8 & Glutinous rice flour & Beef patties & Improve texture quality & {$[33]$} \\
\hline 9 & Flax seed and tomato paste & Beef patties & Improve fatty acid profile and nutritional properties & [34] \\
\hline 10 & Carrots and Oats & Chicken meat cutlet & Higher moisture, lower free fatty acid & {$[35]$} \\
\hline 11 & Finger Millet Flour (eleusinecoracana) & Chicken patties & Improve cooking yield, and moisture retentions. & [36] \\
\hline
\end{tabular}

\section{Addition of antioxidants:}

Meats and meat products are mainly prone to deterioration as they are rich in nutritional composition [37] and moisture content [38]. Addition of spices, herbs, and vegetables extract to raw and cooked meat enhance total antioxidant capacity that is considered important criteria for the shelf life of the meat products, decrease lipid oxidation and improve colour stability [14]. Lipid oxidation decreases food's nutritional quality due to loss of essential fatty acids and vitamins and results in a toxic reaction in the muscles foods such as malonaldehyde (MDA) and COPs, i.e. cholesterol oxidation products [39, 40]. There are various methods for controlling lipid oxidation, among which use of natural antioxidants are the most reliable, effective, convenient and economical. An antioxidant such as herb stabilizes food lipids and thereby inhibits the quality deterioration of the products and also increases the shelf life of the products. Herbs also reduce risk of diseases and promote healthy well being due to their role to protect the body against oxidative damage. Antioxidants are those substances which, when present in food or the body at low concentrations delays or prevent an oxidative process that leads to quality deterioration in food and initiates degenerative diseases in the body. Lipid oxidation may occur via auto-oxidation, photooxidation, thermal oxidation, and enzymatic oxidation and mostly involve free radicals and other reactive species as the intermediate [41]. Auto-oxidation is the reaction between atmospheric oxygen and lipids and is one of the common causes behind the oxidative deterioration of food and biological systems. The thermal oxidation refers to the process that can be accelerated at higher temperatures as experienced during deep fat frying. It leads to elevated levels of free fatty acids and polar matters, foaming, color, and viscosity. The process that involves photo sensitizer excitation and transfer of energy to lipid molecules or oxygen are mainly referred to as photo-oxidation. Enzymes, such as lipoxygenases also catalyze fatty acid oxidation and are usually inactivated in thermal processing of food. Natural antioxidants are derived from plants, animals and microorganisms and synthetic materials from chemicals. Plants and their constituents are natural inhabitants of antioxidants like tocopherols and polyphenols found mainly in spices, herbs, fruits, vegetables, cereals, grains, seeds, teas, and oils. Some antioxidants are also of marine origin, i.e., from algae, shellfish and marine bacteria [42, 41]. By-products obtained from the food and agricultural industries have been reported for their potential use as antioxidants like hulls; shells and skins of nuts and cereals; citrus peels and seeds; canola meal. Fish viscera extracts have also been found to possess antioxidant activity [43]. Synthetic antioxidants are derived from chemicals namely butylated hydroxyanisole (BHA), butylated hydroxytoluene (BHT), propyl gallate (PG) and tertiary-butyl hydroquinone (TBHQ) has been extensively used as food preservatives because of their low cost and bland flavor. Primary oxidation of lipid in meat products leads to cardboard flavor and with progress results in the development of rancid and oxidized flavor [44]. Antioxidant-rich sources are mainly fruits and vegetables $[45,46]$ and serve as a natural source of antioxidants in 

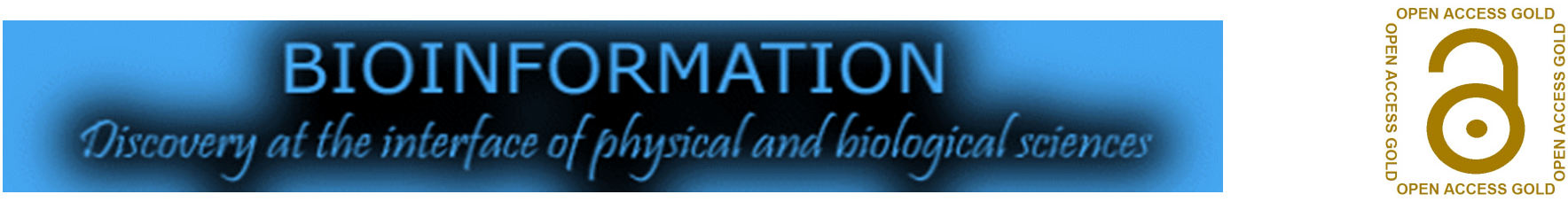

meat products. It contains water-soluble vitamin such as ascorbic acid, flavonoids as well as fat-soluble vitamins and precursors like tocopherols and carotenoids. Antioxidants are chemical compounds that donate hydrogen to the free radicals and reduce rancidity and delayed lipid per-oxidation without altering sensory or nutritional properties of meat products [47]. It has been reported that in last few years for meat product preservation butylated hydroxyanisole (BHA), butylated hydroxytoluene (BHT) and tertiary butyl hydroquinone (TBHQ) have been used as a synthetic antioxidant [48]. However, synthetic chemicals used as an antioxidant often result in adverse effects on human health. So, the consumers are interested in the natural source of antioxidant for the application in meat products. Many studies reveal the addition of natural antioxidant in meat products improved the antioxidant properties and colour stability, reduced lipid oxidation, which improves the shelf life of the products (Table 2).

Table 2: Functional ingredients as a natural antioxidant in different types of meat products

\begin{tabular}{|c|c|c|c|c|}
\hline S.N & Functional ingredients & Developed Product & Effect on meat product quality & Reference \\
\hline 1 & Aqueous extract curry leave and fenugreek leaves & Raw chicken meat products & Improve antioxidant activity & [49] \\
\hline 2 & Clove powder & Chicken patties & Anti microbial properties & {$[50]$} \\
\hline 3 & Pomegranate rind powder & Chicken patties & Antioxidant potential & [51] \\
\hline 4 & Guava & Sheep Meat Nuggets & Improve antioxidanrt and dietryfiber & [52] \\
\hline 5 & Tea polyphenol & Pork sausages & $\begin{array}{l}\text { Antioxidant antimicrobial properties,Inhibit TBARs } \\
\text { value }\end{array}$ & [53] \\
\hline 7 & Rosemary extract & $\begin{array}{l}\text { Raw and precooked pork } \\
\text { sausages }\end{array}$ & Delay TBARS value & [54] \\
\hline 8 & Extracts of kinnow rind, pomegranate rind and seed powders & Goat Meat Patties & Antioxidant & [55] \\
\hline 9 & Fenugreek Seed Flour & Beef burger & Antioxidant and Antimicrobial properties & [56] \\
\hline 11 & Broccoli powder extract & Goat meat products & Antioxidant effect & [57] \\
\hline 12 & Ground mustard & Chicken nuggets & Lower TBARS value, anti microbial properties & [58] \\
\hline
\end{tabular}

\section{Conclusion:}

Meat and meat products are good sources of protein that suffices the requirement of an individual. In order to enhance the nutritional quality, texture, flavour, color and shelf life of the meat products the inclusion of functional ingredients is of paramount importance. The incorporation of the functional ingredient in meat products reduces the possibilities of risk to chronic diseases. The increasing concept of using food for health benefits along with nutrition gives new opportunity to the meat industry. The addition of dietary fibre and natural herbs, which serve as a potential source of fibre and anti-oxidants respectively, fulfills the demand of the consumers for foods with functional value. Hence, the known functional ingredients in meat products are summarized in this report.

\section{Acknowledgment:}

Authors would like thanks University Grant Commission (UGC) for Junior Research Fellowship (UGC-JRF) for the financial assistant.

\section{Conflict of Interest:}

There is no financial/commercial conflict of interest.

\section{References:}

[1] Biesalski HK, Meat Science 2005 70:509 [PMID: 22063749]

[2] Bender AE, FAO Food Nutr Pap. 1992 53:1 [PMID: 1300286]

[3] Kumar V et al. Int. J. Food Sci. Technol. 2010 461:122
[4] Webb EC et al. Small ruminant research 2005 60: 153

[5] Arain MA et al. Pakistan Journal of Nutrition 2010 9:422

[6] Schonfeldt HC et al. Meat Science 1993 34:363. [PMID: 22060744]

[7] Schonfeldt HC et al. Meat Sci. 1993 34:381. [PMID: 22060745]

[8] Serrano A et al. Trends Food Sci Technology 2007 12:401.

[9] Stanton C et al. Curr. Opin. Biotech. 2005 16:198[PMID: 15831387]

[10] Niva M, Appetite 2007 483:384-393 [PMID: 17166625]

[11] Drozen M \& Harrison T. Nutraceuticals World, 1998 1:18.

[12] Cofrades S et al. J Food Sci, 2000 652:281.

[13] Stauffer CE, Baking Snack 1998 20:44.

[14] Diplock AT et al. British Journal of nutrition 1999 81:1

[15] Hygreeva D et al. Meat Science 2014 98:47. [PMID: 24845336]

[16] Vendrell-Pascuas S et al. Journal of Chromatography A 2000 881:591 PMID: 10905738]

[17] National Cancer Institute US Department of Health and Human Services, NIG Pub. 1984 85:2711.

[18] Mansour EH \& Khalil AH, Food Res. Int. 1997 30:199.

[19] Prosky L,Trends Food SciTechnol1999 10:271.

[20] AACC: The definition of dietary fiber. 2001. AACC report. Cereal Foods World, 46: 112.

[21] Elleuch M et al. Food Chem, 2011 124:411.

[22] Mehta N et al. J Food SciTechnology 2015 52:633. [PMID: 25694673]

[23] Schatzkin A et al. Am J Clinical Nutrition 2007 85:1353. [PMID: 17490973] 


\section{BIOINFORMATION \\ Discovery at the interface of physical and biological sciences}

[24] Streppel MT et al. Arch Intern Med, 2005 165:150. [PMID: 15668359]

[25] Grigelmo-Miguel N, Meat Science 1999 52:247. [PMID: 22062572]

[26] Zargar FA et al. SpringerPlus 2014 3:39. [PMID: 24494185]

[27] Mehta et al. Haryana Veterinarian 2013 52:6.

[28] Ibrahium MI et al. Sciences2015 5:645

[29] Soncu ED et al. Korean journal for food science of animal resources 2015 35:370. [PMID: 26761851]

[30] Kumar V et al. Journal of food science and technology 2013 50: 1058. [PMID: 24426017]

[31] Verma AK et al. Asian-Australasian journal of animal sciences 2013 26:886. [PMID: 25049864]

[32] Kausar T et al. Biochem. Cell. Arch. 2018 2: 1569.

[33] Yi H C et al. Meat science 2012, 924: 464. [PMID: 22682071].

[34] Valenzuela-Melendres $\mathrm{M}$ et al. CyTA-Journal of Food 2018 16:263.

[35] Gupta R et al. International Journal of Food and Fermentation Technology 2017 71:41-53.

[36] Naveena BM et al. Journal of Muscle Foods 2006 171:92.

[37] Devatkal et al. J Food Sci Technol. 2011 48:472. [PMID: 23572773]

[38] Enan G1 et al. International Journal of Food Microbiology 1996 30:189

[39] Morrissey PA et al. Meat Science 1998 49:73. [PMID: 22060722]

[40] Tang S et al. International Journal of Food Science \& Technology $200136: 685$.
[41] Shahidi F \& Amarowicz R, Journal of the American Oil Chemists Society 1996 73:1197.

[42] Athukorala Y et al. Journal of Food Lipids, 2003 10:251.

[43] Borderias AJ et al. Trends Food Sci Technol. 2005 16:458.

[44] Angelo A JS et al. Journal of Food Science 199055:1501.

[45] Phillips RW et al. Cancer Research 1993 53: 3723. [PMID: 8339282]

[46] Slattery ML et al. The American Journal of Clinical Nutrition 2000 71:575. [PMID: 10648274]

[47] LahuckyR et al. Journal of the Association of Official Analytical Chemists International 201087: 718.

[48] Faseseas MK et al. Food Chemistry 2007 106:1188.

[49] Devatkal SK et al. Journal of food science and technology2012 49: 781.[PMID:24293699]

[50] Kumar D \& Tanwar VK. Journal of Stored Products and Postharvest Research2011 2: 11.[PMID: 23572818]

[51] Naveena B M., et al. International journal of food science $\mathcal{E}$ technology 2008 43: 1807.

[52] Verma AK et al. Asian-Australasian journal of animal sciences 2013 26: 886. [PMID: 25049864]

[53] Wenjiao F et al. Journal of Food science and Technology 2014 51: 191. [PMID: 24426069]

[54] Sebranek JG et al. Meat science 2005 69:289. [PMID: 22062821]

[55] Devatkal SK et al. Meat Science 2010 85:155.

[56] Hegazy AI. World Journal of Agricultural Sciences 20117:391.

[57] Banerjee R et al. Meat science 2012 91:179.

[58] Devendra K \& Tanwar VK. Journal of food science and technology 2011 48: 759.

Edited by P Kangueane Citation: Kausar et al. Bioinformation 15(5): 358-363 (2019)

License statement: This is an Open Access article which permits unrestricted use, distribution, and reproduction in any medium, provided the original work is properly credited. This is distributed under the terms of the Creative Commons Attribution License 


\section{BIOINFORMATION}

Discovery at the interface of physical and biological sciences
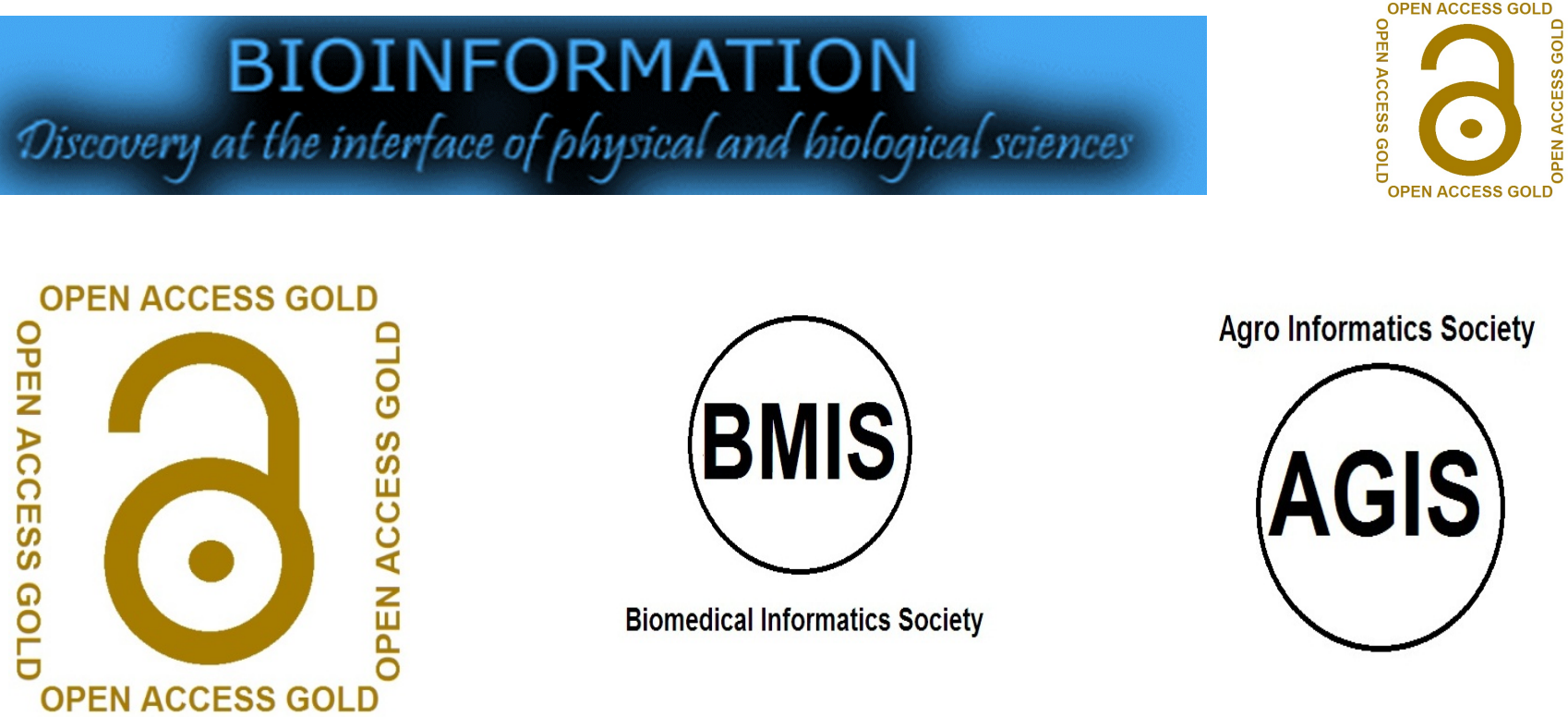

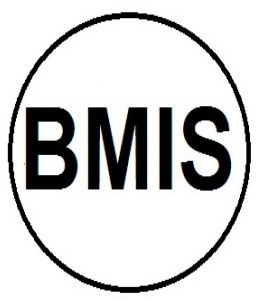

Biomedical Informatics Society

Journal
Agro Informatics Society

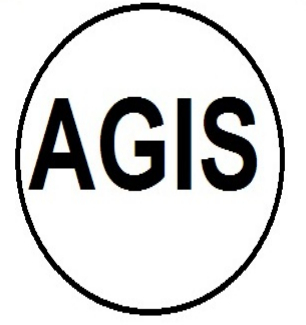

